\title{
Female Genital Mutilation in Sudan: is a new era starting?
}

\author{
Michela Lugiai ${ }^{1}$ - Yasir Shalabi ${ }^{2}$. Vincenzo Racalbuto ${ }^{1} \cdot$ Damiano Pizzol $^{1}$ (D) . \\ Lee Smith ${ }^{3}$
}

Accepted: 23 January 2021 / Published online: 8 February 2021

(c) The Author(s), under exclusive licence to Springer Science+Business Media, LLC part of Springer Nature 2021

\begin{abstract}
The World Health Organisation (WHO) defines female genital mutilation or cutting (FGM/C) as a violation of human rights and includes all procedures that involve partial or total removal of the external female genitalia, or other injury to the female genital organs for non-medical reasons. Sudan has one of the highest rates of FGM/C in the world with $86.6 \%$ girls and women aged between 15-49 years affected. Although FGM/C is still widely practiced across all of Sudan, social attitudes and norms towards the practice are changing, especially in urban areas. On 22 April 2020, the transitional Sudanese government criminalised FGM/C in Sudan when the Sovereign and Ministerial Councils endorsed the amendment to Criminal Law Article 141. Sudan is beginning a new era in terms of FGM/C. In order to achieve effective and long-lasting effects, efficient mechanisms, specifically allocated financial resources, and broader partnerships that include governmental bodies, civil society, community-based organisations, and international actors, must be put in place.
\end{abstract}

Keywords Sudan $\cdot$ Female genital mutilation or cutting $\cdot$ FGM/C $\cdot$ Women

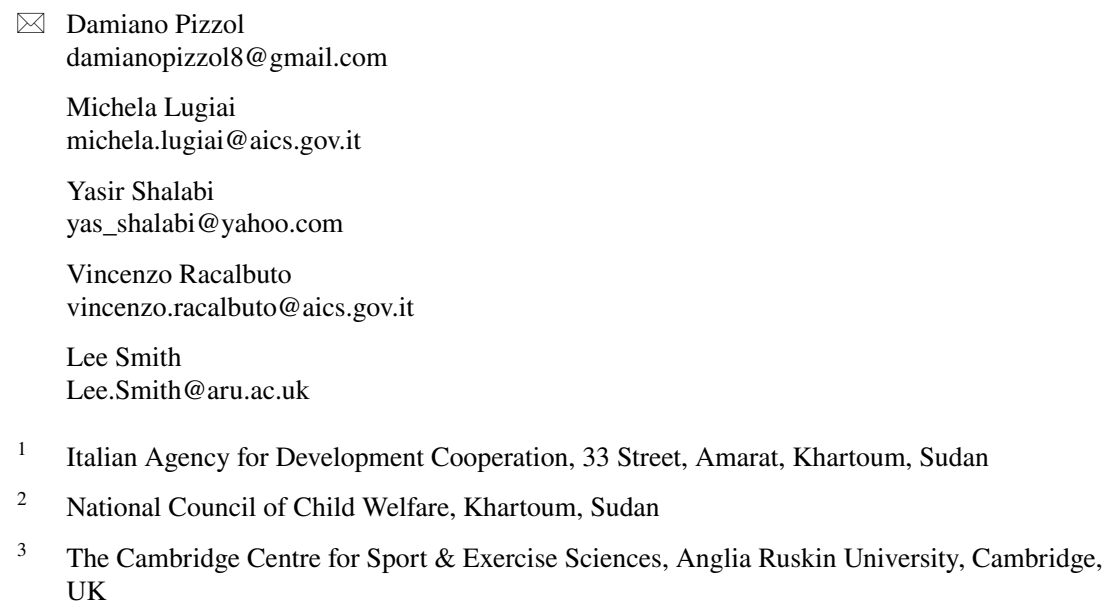


The World Health Organisation (WHO) defines female genital mutilation or cutting $(\mathrm{FGM} / \mathrm{C})$ as a violation of human rights and includes all procedures that involve partial or total removal of the external female genitalia, or other injury to the female genital organs for non-medical reasons (WHO 2020). It is well known that these practices have no health benefits and can cause severe bleeding, problems urinating, and later cysts, infections, as well as complications in childbirth and increased risk of newborn deaths (WHO 2020). It is estimated that this phenomenon affects more than 200 million girls and women especially in Africa, the Middle East and Asia where FGM/C is concentrated (WHO 2020). A recent study by Ahinkorah and colleagues analysed FGM/C characteristics in 12 selected sub-Saharan African countries where this practice is generally predominant (Ahinkorah et al. 2020). Among the selected countries, they showed that overall, $51.7 \%$ of women and $12.9 \%$ of their daughters had undergone FGM/C with the highest proportion of FGM/C in Guinea (96.1\%) (Ahinkorah et al. 2020). Authors confirmed previous findings showing that wealth index, maternal educational status, age of mothers, place of residence (urban versus rural), marital status, occupational status, and media exposure were factors associated with FGM/C (Ahinkorah et al. 2020; Setegn et al. 2016; Gajaa et al. 2016). In particular, the women more exposed to FGM/C seem to be those in the poorest wealth quintile, less educated, older, living in urban areas, married, employed in agriculture and manual works and with lower access to media (Ahinkorah 2020). Unfortunately, this study didn't include Sudan that, from a FGM/C point of view is going through an interesting and potentially revolutionary phase. In fact, FGM/C practices in Sudan started some fifty years ago and recent data showed a prevalence of $87 \%$ among women at reproductive age 15-49 years and 31\% among young girls $(<15$ years) (Bedri et al. 2019). However, recently, a law has been enacted making FGM/C prohibited. In this commentary we discuss the new law in the light of FGM/C Sudanese data and propose a perspective of possible future scenarios for Sudanese women and girls.

According to the 2014 Multiple Indicators Cluster Survey (MICS), Sudan has a FGM/C rate of $86.6 \%$, which is the highest rate of FGM/C in the world (UNICEF 2016). Reasons for practicing FGM/C in the country include socio-cultural and economic factors. FGM/C is a requirement to get married in Sudan, as it is driven by the belief that it maintains intact the virginity of the woman, which is considered as mandatory to engage in a safe marriage. In addition, FGM/C is considered a good hygiene practice in Sudan that enhances both cleanliness and beauty. Although, on one hand, these could be considered valid reasons that allow to understand the existence of these practices, on the other hand, WHO recognises them as a violation of human rights and ascribes them no health benefits (WHO 2020). There are significant differences across regions, strictly related to ethnicity owing to some ethnic groups historically not practicing FGM/C. Those who practice FGM/C also vary according to area of residence. In general, FGM/C is mainly performed by trained midwives $(63.6 \%$ of women who undergone FGM/C), followed y traditional circumcisers $(28.7 \%$ of women who undergone FGM/C). Overall, $31.5 \%$ of girls in the age group 0-14 years have undergone FGM/C (UNICEF 2016). Daughters whose mothers have no education (33.6\%) are more likely to be exposed to the practice of $\mathrm{FGM} / \mathrm{C}$ when compared to daughters whose mothers have a primary education 
(32.7\%), secondary education (28.6\%) and higher education (15.2\%). Finally, women in the poorest households are more likely to support the continuation of the practice $(61.9 \%)$ compared to those in the wealthiest households $(23.3 \%)$ (UNICEF 2016).

FGM/C is still widely practiced across all Sudan, however, importantly social attitudes and norms towards the practice are changing (Badawi and Folcio 2016). Over half of women aged $15-49$ years $(52.8 \%)$ think that FGM/C practice should be abandoned. Highest rates of women favourable to the abandonment of FGM/C are found mostly in urban areas or in states where anti-FGM/C interventions are implemented. This trend is reflected in the legislative framework: Sudan was the first country in Africa to legislate against FGM/C in 1946, criminalising the most severe form of FGM/C known as "pharaonic" (type III, removal of all external genitalia preceding stitching of the vaginal opening), but permitting the locally known "Sunna" form (type I, partial or total removal of the clitoris) (UNFPA/UNICEF 2020). Attempts to enforce the 1946 law were very rare up to 1983, when Sharia law was introduced and the article prohibiting FGM/C was definitely removed from the penal code (Powel 2013). In 2007, the New Women Empowerment National Policy called for the eradication of FGM/C (Kondgen 2010). In addition, the Sudanese Government endorsed the National Strategy for the Abolition of FGM/C (2008-2018) and, in line with this, the National Council for Children Welfare (NCCW), the main responsible governmental body for Child Protection, launched the "Saleema Initiative" in 2008 to promote a positive reframing of the discourse over uncut girls. However, the National Strategy for the Abolition of FGM/C has never been reinforced by supportive laws or policies. In 2009, a proposed ban on FGM/C in the National Child Act failed to materialise. Many states in Sudan have managed to pass laws prohibiting and criminalising all forms of FGM/C, but most of them remained to be enforced or simply appeared to be a political compromise with no penalties for offenders as in the Red Sea State (Al-Nagar et al. 2017).

After years of persistent and forceful advocacy by all stakeholders led by the NCCW, the amendment to the Criminal Law Article 141 was endorsed by both the Sovereign and Ministerial Councils on 22 April 2020. The Article is considered a landmark move by the transitional Sudanese government to criminalise FGM/C in Sudan. The adoption of the Child Act in 2010 was considered as a milestone for the protection of children generally and specifically for children in conflict with the law. However, the implementation of the Child Act has always been challenged with the implementation of the Criminal Act (1991) by judges. The Criminal law of 1991 had contradicted the Child Act in different provisions leading to violations of the Child Rights in Sudan (UNICEF 2016, 2020). The recently amended Article 141 contains the following provisions: (1) There shall be deemed to commit the offence of female genital mutilation whoever, removed, mutilated the female genitalia by cutting, maiming or modifying any natural part of it leading to the full or partial loss of its functions, whether it is inside a hospital, health center, dispensary or clinic or other places; (2) Whoever commits the crime of female genital mutilation shall be punished with three years imprisonment and a fine or closing the premises.

The new Criminal Law, together with Article 141, has become enforceable upon final ratification, on July 10, 2020, almost three months after it passed. 
This leads the discussion on the real chances of enforceability of the law in the Country. Criminalisation and legal reforms might not be enough for Sudan's new law against FGM/C to be useful. Educational and cultural reforms should be supported and promoted. There is still a large stigma attached to girls who have not undergone FGM/C in Sudan. Advocacy and awareness on the enforcement of the law could initially cause an increase in the practice because of the fear of social exclusion or social stigma for not conforming to the norm, which may be stronger than the fear of fines and imprisonment. The Sudanese Government needs to focus first on community awareness to ensure demand and acceptance for the law, which was approved at a Federal level but, most probably, it is still unknown by the majority of local communities. In addition, while this new law may affect the prevalence rate of FGM/C in the coming years, it could also create a new stigma for those girls who have been already cut. Main challenges include not only cultural resistance, but also lack of updated data, misuse of resources and lack of coordination among stakeholders. Finally, the current Coronavirus Disease (Covid-19) pandemic contributed negatively to the practice. During lockdown months in 2020, an increase in the practice was registered across the Country, taking advantage of children being out of schools (UNFPA 2020).

Ending FGM/C is not only a matter of law. Efficient mechanisms, specifically allocated financial resources, and broader partnerships that include governmental bodies, civil society, community-based organisations, and international actors, should be put in place. The law is an essential step that has to be properly enforced, otherwise it could even have harmful effects.

While the overall rate of FGM/C in Sudan is one of the highest in the world, it varies among communities and states. Official updated data and research would enable risk-mapping and help policy-makers and organisations to better identify the economic, social and health consequences of FGM/C, and to target areas with the highest rates of the practice. The law should be aligned with existing or future national strategies and policies, especially concerning Child Protection and Gender Based Violence (GBV). The Government and its partners should be careful in not criminalising different groups including parents, midwives, community leaders and health providers. This could lead to practice FGM/C "underground" and to avoid referral to health centres in case of health consequences for the fear of sanctions. Awareness about the amendment and, most importantly, consensus, should be raised among those groups, ensuring a wider support to social norms change towards new social norms and practices that do not violate human rights (for example providing economic support to midwives or promoting alternative rituals). Academic institutions and media can play a great role in changing the beliefs around FGM/C practice; they could organise media campaigns, promote exchanges with communities abroad and include awareness in the school curricula. In addition, many evaluations have demonstrated that interventions to end FGM/C are more successful if inserted in broader programs to tackle communities' needs and challenges. All these elements have shown in numerous countries to be successful and have led to the creation of an environment where FGM/C no longer has a traditional value (UNFPA/UNICEF 2020). 
In Sudan, the Government, and more specifically the NCCW, are strongly committed to putting in place mechanisms for the creation of an enabling environment to enforce the law. In this regard, the NCCW already established a roadmap that seems aligned with the main elements of success described above. Trainings for law enforcement will be organised for community leaders and health providers. In addition, a Memorandum of Understanding will be established with the media to organise and conduct a communication campaign on the recently ratified law against FGM/C. Finally, the roadmap will be aligned with main national strategies such as the National Health Sector Strategy, the National Girls Education Sector Strategy, the National Social Protection Strategy and the GBV Strategy. These elements, combined with an active partnership between the Sudanese Government and the civil society, show that Sudan has a favourable political and social context to enforce successfully the law and eradicate FGM/C practice. Still, the current economic crisis affecting the Country, together with the global Covid-19 pandemic, could lead to a swift change of priorities and undermine the process of enforcement.

\section{Acknowledgements None}

Author contributions Conceptualisation, M.L. and Y.S.; Data Curation, D.P. and M.L..; Writing - Original Draft Preparation, M.L. and D.P.; Writing - Review \& Editing, L.S and V.R; Supervision, Y.S.

Data availability All data generated or analysed during this study are included in this published article.

\section{Compliance with ethical standard}

Conflict of interest All authors declare no conflict of interest.

\section{References}

Ahinkorah, B. O., Hagan, J. E., Jr., Ameyaw, E. K., Seidu, A. A., Budu, E., Sambah, F., et al. (2020). Socio-economic and demographic determinants of female genital mutilation in sub-Saharan Africa: analysis of data from demographic and health surveys. Reprod Health., 17(1), 162.

Al-Nagar S, Tønnessen L, Bamkar S, Weak law forbidding female genital mutilation in Red Sea State, Sudan, Sudan Working Paper n.1, May 2017.

Badawi ZA, Folcio A, Gender Analysis for Sudan in the framework of the EU Gender Action Plan (GAP) 2016-2020, 2016.

Bedri, N., Sherfi, H., Rudwan, G., Elhadi, S., Kabiru, C., \& Amin, W. (2019). Shifts in FGM/C practice in Sudan: communities' perspectives and drivers. BMC Womens Health., 19(1), 168.

Gajaa, M., Wakgari, N., Kebede, Y., \& Derseh, L. (2016). Prevalence and associated factors of circumcision among daughters of reproductive aged women in the Hababo Guduru District, Western Ethiopia: a cross-sectional study. BMC Womens Health., 22(16), 42.

Kondgen, Olaf (2010) Shari'a and national law in the Sudan. In:Jan Michiel Otto (ed.)Sharia Incorporated: A ComparativeOverview of the Legal Systems of Twelve Muslim Countries inPast and Present. Leiden: Leiden University Press, 181-230

Powell, E. J. (2013). Islamic law states and the International Court of Justice. Journal of Peace Research, 50(2), 203-217. https://doi.org/10.1177/0022343312470275.

Setegn, T., Lakew, Y., \& Deribe, K. (2016). Geographic Variation and Factors Associated with Female Genital Mutilation among Reproductive Age Women in Ethiopia: A National Population Based Survey. PLoS ONE, 11(1), e0145329. 
UNFPA. Millions more cases of violence, child marriage, female genital mutilation, unintended pregnancy expected due to the COVID-19 pandemic. https://www.unfpa.org/news/millions-more-cases -violence-child-marriage-female-genital-mutilation-unintended-pregnancies (Accessed November 2020)

UNFPA/UNICEF. Joint Evaluation of UNFPA-UNICEF Joint Programme onf FGM/C: Accelerating Change. https://www.unfpa.org/admin-resource/unfpa-unicef-joint-evaluation-unfpa-unicef-joint -programme-female-genital (Accessed November 2020)

UNICEF. (2016). Female Genital Mutilation/Cutting (FGM/C) and Child Marriage in Sudan - Are there any changes taking place? An In-Depth Analysis Using Multiple Indicators Cluster Surveys (MICS) Sudanese Household and Health Surveys (SHHSS), 2016.https://www.unicef.org/sudan/reports/ female-genital-mutilationcutting-and-child-marriage-sudan-are-there-any-changes-taking (Accessed November 2020)

UNICEF. (2020). Sudan enters new era for girl rights with criminalization of FGM, April 2020.https ://www.unicef.org/mena/press-releases/sudan-enters-new-era-girl-rights-criminalization-fgm (Accessed November 2020)

WHO. Female genital mutilation. (2020) https://www.who.int/news-room/fact-sheets/detail/female-genit al-mutilation (Accessed November 2020).

Publisher's Note Springer Nature remains neutral with regard to jurisdictional claims in published maps and institutional affiliations. 